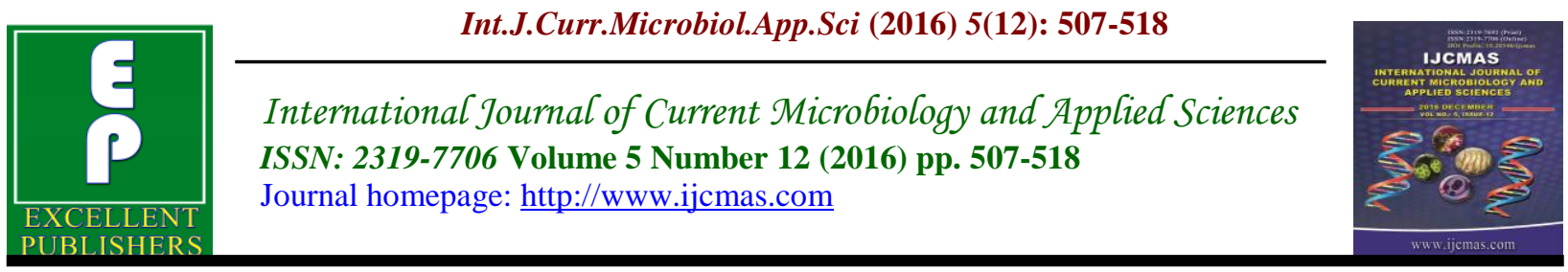

Original Research Article

http://dx.doi.org/10.20546/ijcmas.2016.512.055

\title{
Study the Integration of Bio-Resistance and Magnetic Field in the Fight against Disease Rot Seeds and Seedling Death Caused by Two Fungi Fusarium graminiarum and Rhizoctonia solani on the White Corn Sorghum bicolar L.
}

\author{
Noor K.K. Al-Zubaidi* \\ College of Agriculture - University of Wasit, Iraq \\ *Corresponding author
}

Keywords

Bio-resistance, magnetization irrigation water, Fusarium graminiarum, Rhizoctonia solani.

Article Info

Accepted:

18 November 2016 Available Online: 10 December 2016

\section{A B S T R A C T}

The plastic pots experiment carried out during the months of the seventh and eighth of the year 2016 in order to study the effect of overlap between biogenic resistance and magnetic water to improve the qualities of sorghum plant growth and resistance to fungal pathogens of injury rate by $F$. graminiarum and $R$. solani. Carried out in accordance with the experience of pots full of random design C.R.D. A global experiment with three replications for 45 days study included the use of two fungi T.hamatum and A. niger for the induction of plant resistance against the two fungi $F$. graminiarum and $R$. solani as well as compared to treatment without the use of any fungus. Secondary transactions also included the use of a magnetic field strongly 4000 gauss for magnetization of irrigation water and compare the results with plain water (tap water). The results of the experiment the lack of effect of water magnetized and fungus growth-promoting mentioned on seed germination, while there was a clear effect of the fungus T. hamatum in all the characteristics of the studied growth of (healthy seedling, root length rate, average length of the shoot, wet and dry weight of the plant) as and the effect of fungus $F$. graminiarum since the beginning of the experiment as it led to the rot every plant seeds, while the results of mixing pathogenic fungi and stimulating growth under study noted that there is the effect of the dynamic of the fungus in the growth traits mentioned above. As for secondary treatment (magnetization irrigation water), there was a significant effect clear magnetization of water in the (safty seedling rate, the rate of root length, the length of the shoot rate, wet and dry weight of the plant), while the priority was to fungal bio-resistance and magnetized water to increase the qualities of plant growth studied.

\section{Introduction}

Occupies the sorghum crop Sorghum bicolar L fifth place after wheat, rice, maize and barley, in terms of production and area (FAO, 1998), it is characterized by the possibility of cultivation in most soils newly reclaimed saline and poor soils that are not suitable for the cultivation of other crops (Attia et al., 2001), and expanding the use of Sorghum lot lately, In addition to its use as a food for humans and animals it has been entered as a basic material in the sugar and protein industry, starch and alcohol and in 
the papers and dyes industry, and because of this expansion increased the cultivated him space in the world until it reached more than 40 million hectares (FAO, 2008), In spite of all the advantages enjoyed by the crop's multiple uses and aspects, the cultivation in Iraq is still limited and confined to the side of the feed only, and that of the most important reasons for this is the low productivity of local varieties because of the failure to maintain the purity and for reasons related to the operations of the soil and crop service, which led to the reluctance of farmers for cultivation (Kubaisi, 2001), The continuation of the farmer or producer to follow the traditional methods in the cultivation of this crop, leading to obtaining the amount of production and revenue are close and similar in each growing season or agricultural years, so the introduction of the cultivation methods of modern Lori reduce the cost of the size and the increased revenue may encourage the farmer to this cultivation crop, as it has emerged in recent years technical magnetic Commonly used in various areas of life such as industry (Szkatula et al., 2002), and in improving water and sterilized (Starmer, 1996) also used magnetic technology in the health and medical purposes (Nasser, 2006).

It tended some recent studies in the field of agriculture to employ this technique for the purpose of treatment and improve some properties of the soil (Jawdhiree, 2006), and improve plant productivity and increased growth (Fahd et al., 2005; Hasan et al., 2005; Kaabi, 2006), Even reached employed in the reduction of mycotoxins (Salumee, 2007), also (Vasilevski, 2003) Noting there are road use Biophysical Methods in agriculture can achieve an increase in seed germination by $20 \%-30 \%$ and increase economic winning by $10 \%-50 \%$ and increase the spread of the roots of $24 \%$ and to increase the ability of the plant to various stresses bearing and minimize the use of fertilizers by $10 \%-15 \%$, and reduce the use of pesticides and the contamination of groundwater and reduce production costs.

In the area of plant protection and control of plant diseases, the studies in this area is still limited, if not non-existent originally,. Therefore, this study was designed to detect potential impact of the overlap between the biological resistance and technical magnetic in the inhibition of fungi that cause disease rot seeds and seedlings die corn white rate by $F$. graminiarum and $R$. solani.

\section{Materials and Methods}

\section{Prepare a vaccine fungus used in the study}

In this study, the use of two pathogenic fungi Fusarium graminiarum, Rhizoctonia solani and The two fungi motivators for growth Trichoderma hamatum and Aspergillus niger, The vaccine preparation fungus mentioned planted in the center of media P.D.A. (Potato Dextrose Agar) genitive antibiotic Chloramphenicole by $250 \mathrm{mg} / \mathrm{L}$ before intransigence by five dishes each dishes, all of which were incubated in the incubator at a temperature of $25 \pm 2$ for five days.

\section{Magnetization process water irrigation system and the creation of magnetized water}

Conducted magnetization process water user in this study using a magnetic device with the intensity of 4000 gauss, Magnetic intensity was measured by a device Gaussmeter product by the company Hirst Magnetic Instrument LTD under serial number 4977 GM, in the Ministry of Science and Technology, Department of Technology and Water Treatment. Water 
system manufactured by using a plastic water tanks capacity of 5 liters. It has been reached reservoirs pump on one hand and a rubber tube connecting the magnet on the other hand, where he was a repeat pass the water through a magnet for five minutes between the reservoirs and water collecting in one of them to be used immediately for watering pots.

The effect of irrigation water magnetized and normal use of fungi catalyst for growth in the induction of resistance to the seeds and seedlings of sorghum against pathogenic fungi under study in plastic pots

The preparation of agricultural soil from mixing soil and Pettmos ratio of 1: 1 And sterilized using commercial formalin solution, which consists of 1:50 formalin / water, The solution is used by $3 \mathrm{~L} / \mathrm{m}^{3}$ soil placed in sealed bags, And left for 3 days and then published the soil for 3 days to remove traces of the toxic substance, Then distributed soil in plastic pots with a diameter $7 \mathrm{~cm}$ and depth of $7 \mathrm{~cm}$ quantity of $269 \mathrm{~cm} 3$ (Toajn, 1979), Then was added five tablets of all fungal isolates a diameter of $5 \mathrm{~mm}$ each pot and mix well with the soil, as shown the following transactions.

1- Soil (Control)

2- Soil added vaccine fungus T.hamatum (S.+T.h.)

3- Soil added vaccine fungus A.niger (S.+A.n.)

4- Soil added vaccine fungus R.solani (S.+R.s.)

5- Soil added vaccine fungus F.graminiarum $(\mathrm{S} .+F . g$.

6- Soil added vaccine fungus T.hamatum and R.solani (S.+T.h.+ R.s.)

7- Soil added vaccine fungus T.hamatum and F.graminiarum (S.+T.h.+F.g.)
8- Soil added vaccine fungus A.niger and R.solani (S.+A.n.+R.s.)

9- Soil added vaccine fungus A.niger and F.graminiarum (S.+ A.n.+F.g.)

After three days were planting sorghum seeds (Which have been obtained from the field crops department in the College of Agriculture / University of Basra ), Sterilized surface solution concentration of $10 \%$ of the commercial sodium hiboklorat solution for 3 minutes, It is then washed with distilled water sterilized three times and then dried on filter paper (Whatman-No 5), And then put sterile distilled water for two hours for the swelling and ease of seeds germination and then cultivated by three seeds per pot and repeated three replications and the use of two factors one irrigation water magnetized and the second ordinary tap water.

The germination rate of sorghum seeds account after three days of planting, It was then healthy seedling rate account after 10 days from emergence above the soil surface, Then remove the two and left one in each planter, Then continued watered whenever the need arises, After 45 days of seed germination was calculated root length by (cm) after washing and disposal of suspended soil and dried on filter paper and then calculate the length of the shoot by (cm) and fresh weight of plants by $(\mathrm{g})$, then dried up after the plants oven temperature $70^{\circ} \mathrm{C}$ for two days and while the stability of weight and then the rate of the dry weight of plants is calculated by (g) (Al Heloo, 1995, and al-Moussawi, 1998).

An analysis of data under study, according to the analysis of variance for a perfect design of randomization C.R.D. two factors of global experience and compare the test averages less significant difference L.S.D. At the level of $5 \%$ probability (Al Rawee and Khalaf, 2000). 


\section{Results and Discussion}

The effect of bio- resistance and magnetic irrigation water on germinating seeds and rotting rate by two fungi Fusarium graminiarum and Rhizoctonia solani to plant sorghum

The results of the effect of magnetization of irrigation water added to the seeds planted in pots contaminated fungus pathogen $F$. $g$., $R$. $s$. and The two fungi motivators for growth $T$. $h ., A . n$. and the mixture, set out in Table (1) That there is a significant effect between fungal isolates and the mixture in the germination rate of sorghum seeds, it was the highest rate of the presence of fungus T.h. was (3) seeds and the least was caused by pathogenic fungus $F$. $g$. which amounted to (0.33) seed compared with the comparison treatment averaged seed germination where (3) seeds also, The reason for the failure of germination due to the ability of pathogenic fungi to the secretion of enzymes degrading cellulose, caatin and protein that cause rot the seeds or the secretion of toxic metabolic effect materials, leading to failure of germination (Inoue et al., 2002), while the seed germination rate in other fungal transactions is $(2.5,2,2,2,1.67,1.33)$ isolates the effect of $\{$ R.s., A.n., (T.h. + F.g.), (A.n. + R.s.), $($ T.h. + R.s.), (A.n. + F.g.)\} respectively, clear from the above that the fungus biological resistance T.h. has provided protection for the seeds germinate before the incidence of the fungus pathogen and thereby increase the germination percentage as the bio-resistance fungus has Unsolicited privacy and secretion filtrates chemical effect in biological control of pathogens and increase the percentage of germination in addition to penetration to the inside of the seed and the induction of systemic resistance (Howell et al., 2002). It also shows the absence of significant differences in the treatment of magnetization of the irrigation water that the germination rate (2.15)seeds compared with ordinary water (tap water), which was the rate of germination (1.81) seeds, while there was a significant difference between the overlapping transactions as it was the highest rate of seed germination in the overlap with fungus T.h. in both treatments (magnetized and plain water) and the treatment of fungus R.s. and two fungi mixture (A.n. + R.s.), Which overlapped with magnetized water reaching 3 seed and the least with fungus $F . g$. Which overlap with plain water, which was the rate of germination (0) seed compared with the comparison treatment, which was the rate of germination of seeds (3) Seeds.

Explained Salumee (2007) that the water magnetized role in the reduction of Zeralennon by $99.4 \%$ as well as the inhibition of the growth of fungus Fusarium graminearum on growth media by $30.1 \%$.

The expected results as a result of exposure to magnetic field (whether positive or negative) depends on the physiological condition targeted organism (Jerman et al., 1996; Ruzic and Jerman, 1998) as well as environmental factors and biological and other overlapping with the magnetic field (Ruzic et al., 2000).

The effect of overlap between the vital factor with irrigation water magnetization in maintaining sorghum planted in pots with soil treated fungus $F$. graminiarum and $R$. solani for her safety after 10 days of germination

The results of the Table (2) the absence of significant differences between the treatment fungus catalyst for growth T.h. and the treatment of comparison, reaching the highest rate of the plant healthy after 10 days from germination (3) seedling, 
compared with the control treatment, which was average (2.83) seedling, while there was a clear effect of pathogenic fungi under study on seedlings, it caused fungus $F . g$. to kill plants fully either growing plants in soil contaminated with fungus R.s. the average (0.33) seedling, it is shown in the table below that of water magnetized significant effect compared to irrigate seedlings with plain water, reaching unscathed seedlings irrigated with magnetized water (1.63) seedling, compared with ordinary water, which was the rate of seedlings (1.04) seedling, the reason for this is that it is accompanied by the magnetization of irrigation water a range of chemical and physical changes of water including increasing the dissolved oxygen ratio and reducing the surface tension and increase the solubility of solids and increase the electrical conductivity and increase the readiness of nutrients in soil and improve the permeability of the cell membrane and low viscosity compared with standard water (Sueda et al., 2007; Toledo, 2008), while there were significant differences clear between the overlap transactions between fungal isolates under study magnetic field, Scarselletti and Faull (1994) has pointed out the existence of a strong relationship between the production Pyrone by the fungus Trichoderma spp and its ability to antagonism with R.solani and F.oxysporum extracellular, also it found that the fungus $T$. viride stimulates defensive response to cotton seedlings against fungus R.solani when packaging seeds by germs resistant fungus, and by increasing the production of turbine materials (Terpenoids) which increases the effectiveness of the enzyme peroxidase in the roots of the plant against fungus R.solani (Howell et al., 2002). The use of the fungus Trichoderma spp. led to a significant reduction in the severity of the injury to plants damping off disease, and the roots rot and wilt caused by soil-borne fungi and portable seeds such as Fusarium spp. and Sclerotium spp. and Verticillium dahliae and M.phaseolina (Whipps, 1987; Datnoff, et al., 1993; Al-Chaabiand and Matrod, 1994; Jabara, 2002; Kucuk and Kivance, 2003), while noted Diwan (2001) that the fungus Fusarium was more prominent on dead seedling of all the fungi causing wilting tomatoes all year round.

The interaction effect between the bioresistance and magnetizing irrigation water along the root and vegetative by (cm) to plant sorghum after 45 days of germination

The results of Table (3) that there is a clear role for fungi stimulating the growth of fungal T.h. and A.n. to increase the length of root to plant corn, which reached $(21.83,16.33 \mathrm{~cm})$ respectively, the least the length of it was due to pathogenic fungi R.s. and F.g. which was $(2.67,0 \mathrm{~cm})$ respectively, compared with the comparison treatment, which amounted to $(14.83 \mathrm{~cm})$, there is also a high catalytic effect of water magnetized along the root of the plant was $(14.59 \mathrm{~cm})$ while the length by plain water $(8.22 \mathrm{~cm})$, while the highest radically along to plant corn in the treatment of overlap was due to fungus T.h. contaminated soil that irrigated by magnetized water that reached $(25 \mathrm{~cm})$ compared with the comparison treatment, which amounted to $(17 \mathrm{~cm})$.

As for the shoot, there was also a clear impact of the fungus T.h. solely or when mixed with pathogenic fungi under study was the length of the shoot $(36 \mathrm{~cm})$ and reached when mixing mentioned fungus with pathogenic fungi R.s., F.g. (33.67, $18.33 \mathrm{~cm}$ ) while the length of the shoot to plant sorghum contaminated by fungus $A . n$. $(25.67 \mathrm{~cm})$ and when mixed with the two fungi nurses R.s. and F.g. $(15.17,11.17) \mathrm{cm}$, respectively, compared with the comparison 
treatment that the length of the shoot where $(20.67 \mathrm{~cm})$ and that this increase may be due to the decomposition of organic materials by fungus Trichoderma spp. which in turn frees large amounts of carbon dioxide and therefore carbonic acid, which increases the efficiency of the process of photosynthesis, thus increasing the shoot (AL Hadithi, 2002), on the other hand, it was working to curb the infection fungus pathogen and increase the readiness of nutrients for plants such as nitrogen, sulfur and phosphorus, as it increases the absorption efficiency micronutrients $\mathrm{Mn}, \mathrm{Fe}, \mathrm{Zn}, \mathrm{Cu}$ and therefore increase the readiness of the plant and improve shoot and root growth (Altomar et al., 1999; Dewan et al., 2007), the results show the table that the water magnetized big role in increasing the shoot to plant sorghum was $(22.59 \mathrm{~cm})$ compared with ordinary water, which was $(13.74 \mathrm{~cm})$, while the results showed that the overlap between the vital impact and water significant differences clear, ranging from $(0-47 \mathrm{~cm})$.

The effect of treatment soil biogenic resistance fungi and magnetic irrigated water in wet weight by (g) to plant sorghum after $\mathbf{4 5}$ days from germination

The results of Table (4) that the fungus resistance biogenic T.h. Significant effect with fungal transactions where he scored the highest weight of a wet plant sorghum, which amounted to (3.91g) compared with the comparison treatment, which amounted to $(2.76 \mathrm{~g})$ while less humid weight was recorder with pathogenic fungi which reached (0) with fungus $F . g$. and $(0.85 \mathrm{~g})$ with fungus R.s..

Table.1 the effect of irrigation water magnetized and plain water in the germination rate of sorghum seeds planted in pots with soil contaminated by the fungus $F$. graminiarum and $R$. solani and two fungi motivators for growth T.hamatum and A. niger

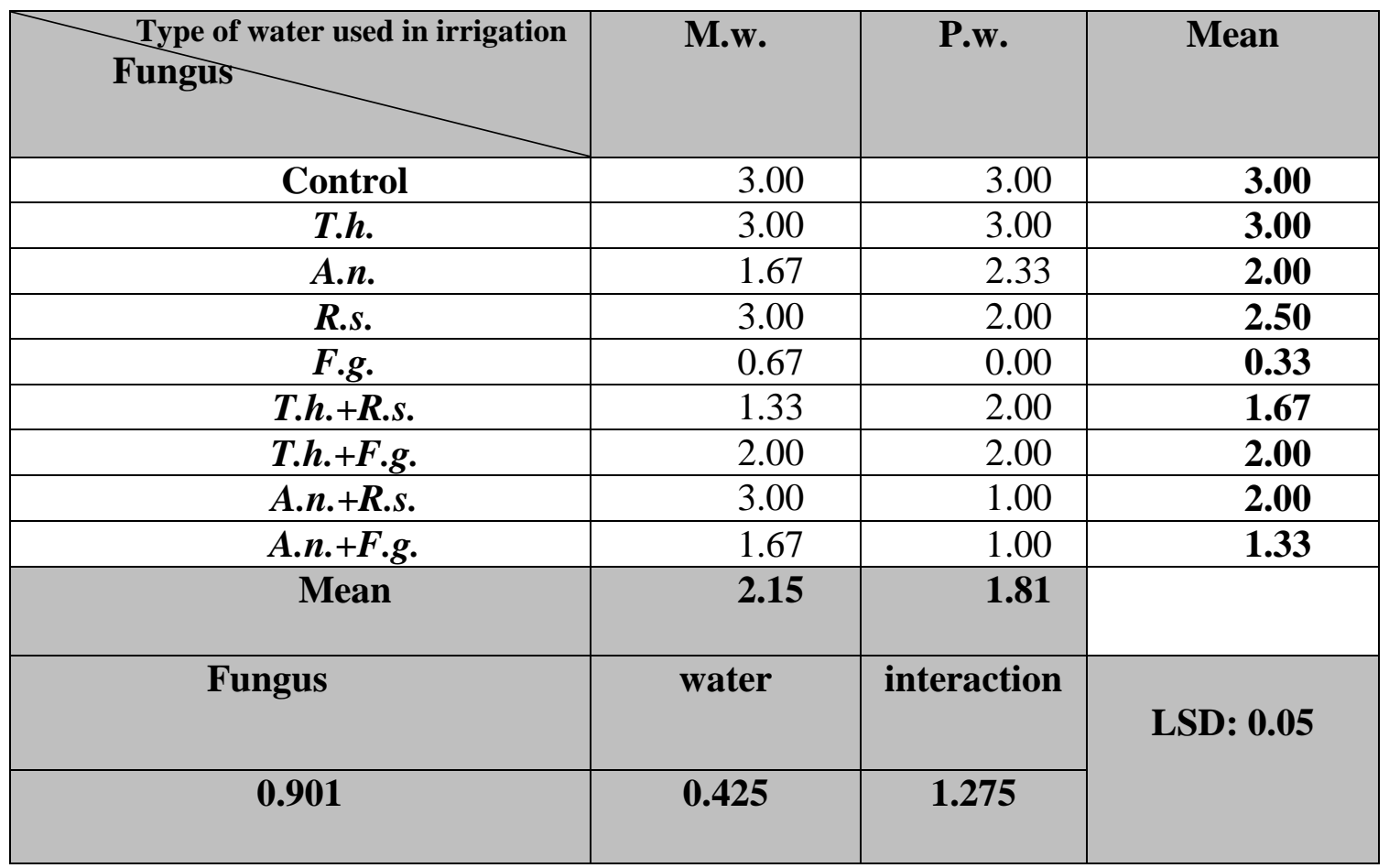


Table.2 the effect of irrigation magnetized water and normal maintain sorghum planted in pots with soil treatment of fungal pathogens $F$. graminiarum and $R$. solani and two fungi motivators for growth T. hamatum and A. niger and the mixture on the safety of 10 days after germination.

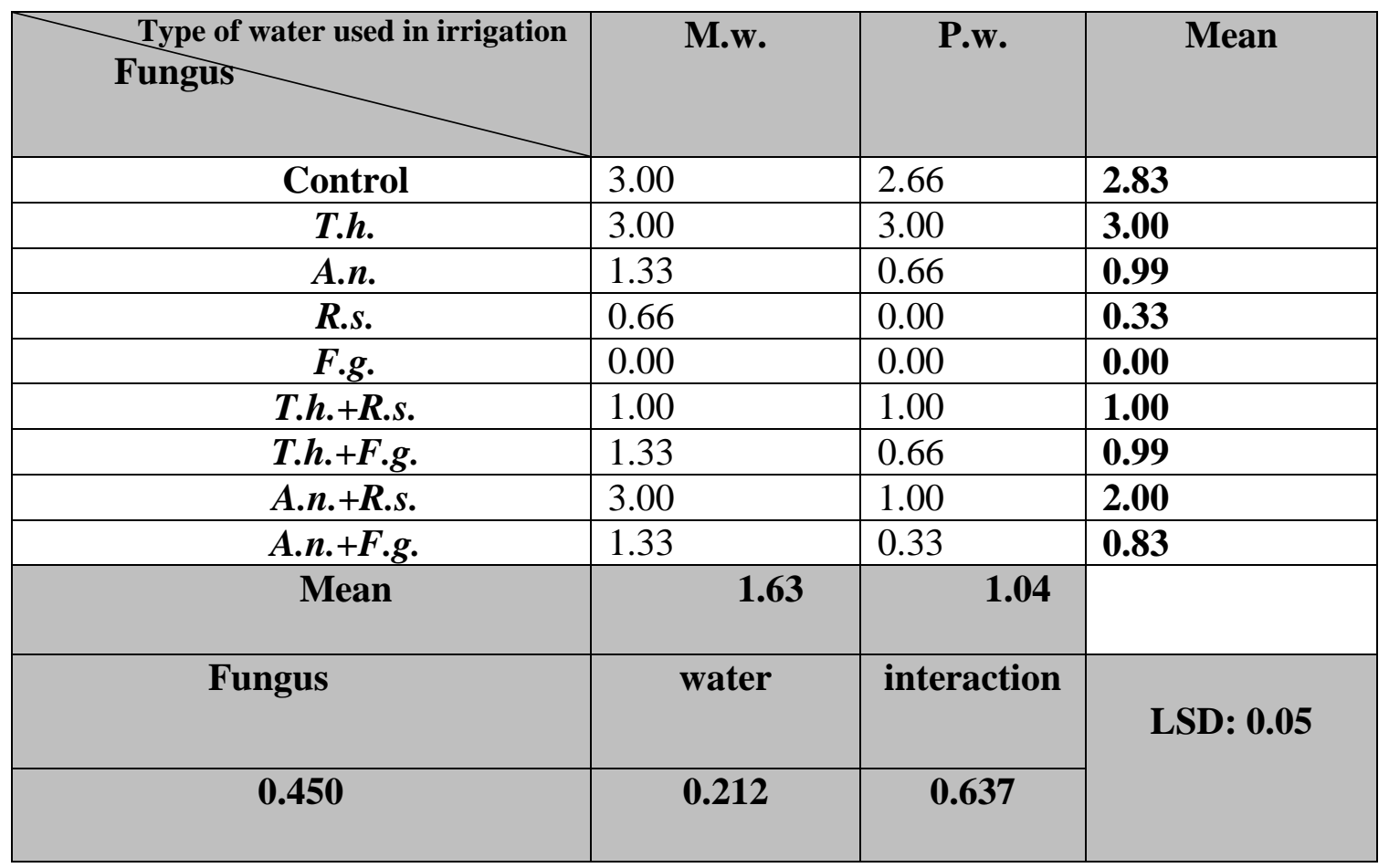

Table.3 the effect of overlap between the biogenic resistance and the magnetized water along the root and vegetative by $(\mathrm{cm})$ to plant sorghum after 45 days of germination

\begin{tabular}{|c|c|c|c|c|c|c|c|}
\hline \multirow{2}{*}{\multicolumn{2}{|c|}{$\begin{array}{l}\text { growth standard } \\
\text { Type of water used in irrigation } \\
\text { Fungus }\end{array}$}} & \multicolumn{3}{|c|}{ root length $(\mathbf{c m})$} & \multicolumn{3}{|c|}{ The length of the shoot $(\mathrm{cm})$} \\
\hline & & M.w. & P.w. & Mean & M.w. & P.w. & Mean \\
\hline \multicolumn{2}{|c|}{ Control } & 17.00 & 12.67 & 14.83 & 22.67 & 18.67 & 20.67 \\
\hline \multicolumn{2}{|c|}{ T.h. } & 25.00 & 18.67 & 21.83 & 40.00 & 32.00 & 36.00 \\
\hline \multicolumn{2}{|c|}{ A.n. } & 21.33 & 11.33 & 16.33 & 29.00 & 22.33 & 25.67 \\
\hline \multicolumn{2}{|c|}{ R.s. } & 5.33 & 0.00 & 2.67 & 5.67 & 0.00 & 2.83 \\
\hline \multicolumn{2}{|c|}{ F.g. } & 0.00 & 0.00 & 0.00 & 0.00 & 0.00 & 0.00 \\
\hline \multicolumn{2}{|c|}{ T.h.+R.s. } & 13.33 & 10.33 & 11.83 & 47.00 & 20.33 & 33.67 \\
\hline \multicolumn{2}{|c|}{ T.h.+F.g. } & 21.33 & 10.33 & 15.83 & 23.67 & 13.00 & 18.33 \\
\hline \multirow{2}{*}{\multicolumn{2}{|c|}{ A.n.+R.s. }} & 11.33 & 7.33 & 9.33 & 19.33 & 11.00 & 15.17 \\
\hline & & 16.67 & 3.33 & 10.00 & 16.00 & 6.33 & 11.17 \\
\hline \multicolumn{2}{|c|}{$\frac{A . n .+F . g .}{\text { Mean }}$} & 14.59 & 8.22 & & 22.59 & 13.74 & \\
\hline \multirow{2}{*}{ LSD: 0.05} & Fungus & water & interaction & & Fungus & water & $\begin{array}{c}\text { interactio } \\
\text { n }\end{array}$ \\
\hline & 5.699 & 2.686 & 8.059 & & 6.417 & 3.025 & 9.076 \\
\hline
\end{tabular}


Table.4 the effect of treatment soil biogenic resistance fungi and magnetic irrigated water in wet weight $(\mathrm{g})$ of the plant sorghum after 45 days from germination

\begin{tabular}{|c|c|c|c|}
\hline Type of water used in irrigation & M.w. & P.w. & Mean \\
\hline Control & 3.13 & 2.40 & 2.76 \\
\hline T.h. & 4.66 & 3.16 & 3.91 \\
\hline A.n. & 3.73 & 2.17 & 2.95 \\
\hline R.s. & 1.70 & 0.00 & 0.85 \\
\hline$F . g$. & 0.00 & 0.00 & 0.00 \\
\hline T.h.+R.s. & 2.76 & 1.26 & 2.01 \\
\hline T.h.+F.g. & 2.50 & 1.56 & 2.03 \\
\hline A.n.+R.s. & 2.13 & 1.30 & 1.71 \\
\hline A.n.+F.g. & 3.73 & 0.34 & 2.03 \\
\hline Mean & 2.70 & 1.35 & \\
\hline Fungus & water & interaction & \\
\hline 0.772 & 0.364 & 1.093 & \\
\hline
\end{tabular}

Table.5 the effect of the treatment of soil by biogenic resistance fungi and magnetic irrigate water in the dry weight of the plant sorghum after three days of the expense of wet weight

\begin{tabular}{|c|c|c|c|}
\hline Type of water used in irrigation & M.w. & P.w. & Mean \\
\hline Control & 0.907 & 0.687 & 0.790 \\
\hline T.h. & 1.117 & 0.937 & 1.020 \\
\hline A.n. & 0.373 & 0.253 & 0.310 \\
\hline R.s. & 0.037 & 0.000 & 0.010 \\
\hline F.g. & 0.000 & 0.000 & 0.000 \\
\hline T.h. + R.s. & 0.273 & 0.573 & 0.420 \\
\hline T.h.+F.g. & 0.100 & 0.023 & 0.060 \\
\hline A.n.+R.s. & 0.077 & 0.043 & 0.060 \\
\hline A.n.+F.g. & 0.060 & 0.007 & 0.030 \\
\hline Mean & 0.327 & 0.280 & \\
\hline Fungus & water & interaction & LSD: 0.05 \\
\hline 0.095 & 0.044 & 0.134 & \\
\hline
\end{tabular}


The increase in wet and dry weight may be due to the ability of fungi biological resistance to excrete some of the toxic substances of pathogenic fungi (AL Bahadli et al., 1986), and showed the same results that the effect of magnetized water in the wet weight of the plant was plant weight coefficient by $(2.7 \mathrm{~g})$ while the weight with plain water (1.35g) as for the overlap between the water and fungal isolates there was a big significant difference was the highest wet weight of plants irrigated with water magnetized and factories fungus T.h. was $(4.66 \mathrm{~g})$ and the very least with the two fungi $F . g$. and R.s. was $(0 \mathrm{~g})$.

In a study conducted by $\mathrm{Al}$ Adjadjiyan (2002) targeted he effect of the magnetic field in some growth standards to plant yellow corn has got a significant increase in wet weight of shoots and plant height when treated seed corn magnetic field intensity 1500 gauss (0.15 tesla) for ten minutes, as it happened (Racucin et al., 2006) similar results when exposing the seedlings of corn to a magnetic field intensity $50-250$ milli tesla (500-2500 gauss) for 11 days, and $\mathrm{Al}$ Maadida (2006), which pointed to the existence of a significant increase in fresh and dry weight of root and shoot of the plant Zinnia elegans when magnetized irrigation water intensity 500-1500 gauss.

The effect of the treatment of soil biogenic resistance fungi and magnetic irrigate water in the dry weight of the plant sorghum after three days of the expense of wet weight

Results from Table (5) that biogenic resistance Fungi role in dry weight increase to plant sorghum was the highest dry weight of the plant $(1.02 \mathrm{~g})$ when the treatment of the soil fungus T.h., while the fungus pathogen R.s. role in reducing the dry weight of the plant where he was $(0.01 \mathrm{~g})$ compared with the comparison treatment, which amounted to $(0.79 \mathrm{~g})$, also shows that the water magnetized role in dry weight increase of the plant has been found that the average weight was $(0.327 \mathrm{~g})$ compared with ordinary water, which reached $(0.28 \mathrm{~g})$ while the plant weight in the overlap between the water and fungi different, reached above the soil treated fungus T.h. and irrigated water magnetized was $(1.117 \mathrm{~g})$ and the very least with pathogenic fungi under study R.s. and F.g. both when irrigate the soil with water magnetized or normal.

Also it found (Racucin et al., 2006) an increase in the dry weight and wet and lengths seedling corn exposed to a magnetic field ranging from a magnitude of between 50-250 milli tesla for a period of 11 days, and agree the above results with what says (Elfadil and Abdallah, 2013) at the irrigation plant sorghum magnetized water led to a noticeable increase in fresh and dry weight of the plant and also the results agreed with what he got (Al Mashhadani et al., 2016) at the treatment plant wheat class (Digila, Furrat and Tamooz) by magnetized water led to an increase in standards plant growth (weight of roots wet and dry, the plant wet and dry weight).

\section{References}

Al Adjadjiyan, A. 2002. Study of the influence of magnetic field on the some biological characteristics of Zea mais. J. Central European Agri., 3(2): 89-94.

AL Bahadli, A.H., Ayad A.W.H., Mohammed, B.H., Moatasem S.A. 1986. Infecting tomato fruits of the fungus Alternaria alternata and toxins produced by. Fourth Scientific Conference of the Scientific Research Council. Proceedings of agricultural research, (3): 1531-1537. 
AL Hadithi, B.A.A. 2002. Enzymatic activity of the fungus Trichoderma harzianum in soil and plant growth holds tomato. PhD thesis. College of Agriculture, Baghdad University

AL Heloo, Y.A.S. 1995. Some fungi accompanying the roots of the tomato and its relationship to the growth of the host and the death of seedling disease caused by fungus Fusarium oxysporum f.sp.lycopersici. M.Sc. thesis, Collage of Agriculture, University of Basra 0.62 pages.

AL Jawdhiree, H.W.A. 2006. The effect of water quality and the magnetization and the levels of potassium fertilizer in some chemical characteristics of soil and growth holds the yellow corn. M. Sc. thesis, Department of Soil and water. College of Agriculture, Baghdad University, 135 p.

AL Kaabi, M.J.M. 2006. The effect of the use of magnetized water in irrigation and spraying urea, iron and zinc in the growth of the local orange seedlings. M.Sc. thesis, Department of Horticulture. College of Agriculture. Baghdad University 0.101 p.

AL Kubaisi, M.I. 2001. The impact of the dates and methods of adding nitrogen fertilizer to the growth of crop cultivars of sorghum M. Sc. thesis Collage of Agriculture - University of Baghdad, Iraq.

AL Maadida, A.F.Q. 2006. The effect of magnetic technology in some ornamental plants. Doctoral thesis. Department of Horticulture. College of Agriculture, Baghdad University. I $150 \mathrm{p}$.

AL Moussawi, L.A.L. 1998. The study of throw fungi and fungal pathogens of okra seedlings present in the soils some areas of Basra. M.Sc. thesis -
College of Science - University of Basra. 119 pages.

AL Rawee, K.M., A.A. Khalaf. 2000. Design and analysis of agricultural experiments. The Ministry of Higher Education and Scientific Research. University of Al Mosul. National Library institution for printing and publishing. $488 \mathrm{p}$.

AL Tomare, C., Norvell, W.A., Bjorkman, T. and Harman, G.E. 1999. Solubilization of phosphates and micronutrients by the plant growth promoting and biocontrol fungus Trichoderma harzianum Rifai 129522. Appl. Environ. Microbiol., 65: 2926-2933.

Al-Chaabiand, S. and Matrod, L. 1994. Evaluation of biocontrol efficacy on pathogenic. Soil borne fungi. Arab J. Pl. Prot., 12 (1):49

Al-Mashhadani, I.I.H., Khalid A.R., Eman, N.I., Salah M.H. 2016. Effect of Magnetic Water Treatment on Salt Tolerance of Selected Wheat Cultivars. J. Int. Environ. Application \& Sci., Vol. 11(1): 105109.

Attia, H.J., Khudair, A., Zafer, J.A. 2001. The effect of plant density and fertilization in the growth and holds sorghum. Iraqi J. Agri. Sci., Volume 32 Issue 2005.

Datnoff, LE., Nemec, S. and Pochronezy, K. 1993. Biological control of Fusarium crown and root rot of tomato. Phytopathol., 83: 1046-1047.

Diwan, M.M. 2001. Practical and effective way to resist the life of wilting tomato diseases using animal manure as a carrier of the fungus T.harzianum. Babylon Magazine, Volume 6 Number 3.

Diwan, M.M., Adraa I.S., Cahaeer M. 2007. The effect of micronutrients in enhancing the capacity of fungus 
Trichoderma harzianum Rifai to improve okra plants wilt resistant Rhizoctonia growth. Accepted for publication in the Journal of the University of Karbala scientific.

El Fadil, A.G., R.A. Abdallah. 2013. Effect of light, ultra violet and magnetized water on the growth and development of Dura (Sorghum sp.). Agri. Biol. J. North America, ISSN Print: 21517517, ISSN Online: 2151-7525, doi:10.5251/abjna.2013.4.2.91.96 () 2013, Science Huß, http://www.scihub.org/ABJNA

Fahed, A.A., Koutaiba, M.H., Adnan, H.F., Tariq, L.R. 2005. Adaptation Magnetic of properties to salt water for crops: yellow corn and wheat. Iraqi J. Agri. Sci., 0.36(1): 29-34.

FAO. 1998. year Book. Production.V.52. FAO. 2008. https://www.faostata.fao.org/site

Hassan, K.M., Ali F., Adnan F.H., Tariq, L.R. 2005. Adaptation Magnetic of properties to salt water for irrigation purposes sunflower crop. Iraqi $J$. Agri. Sci., 0.36(1): 25-28.

Howell, C.R., Hanson, L.E. Stipanovic, R.D. and Puckber, L.S. 2002. Introduction of trepenoid synthesis in cotton root and control of Rhizoctonia solani by seed treatment with Trichoderma vi. Phytopathol., 90: 248-252

Inoue, I., Namiki, F. and Tsuge, T. 2002. Plant colonization by vascular wilt fungus Fusarium oxysporum requires FOW1, age coding amitochondrial protein. The Plant Cell, American Society of Plant Biologists, 14:18691883.

Jabara, I.M. 2002. The effect of solar pasteurization in survival of the pesticide resistance biogenic challenge Trichoderma harzianum and Paecilomyces lilacinus steadfastness in the fight against some of the roots of disease in protected agriculture. M. Sc. thesis College of Agriculture - University of Baghdad.

Jerman, I., M. Berden., and R. Ruzic. 1996. Biological influence of ultraweak supposedly EM radiation from organisms mediated throngh water. Electro and Magnetobiol., 15(3): 229244.

Kucuk, C. and Kivance, M. 2003. Isolation of Trichoderma spp. and determination of their antifungal, biochemical and physiological features. Turk. J. Biol., 27: 247-253

Nasser, K.A.A. 2006. The effect of the use of magnetized water in some aspects of performance in rats. Master Thesis. Genetic Engineering Institute and ecological technologies for postgraduate studies. Baghdad University.

Racucin, M., G.H. Calngaru and D.E. Creanga. 2006. Static magnetic field influence on some plant growth. Rom. J. Phys., 51(1-2): 245-251.

Ruzic, R., D. Vodnik and I. Jerman.2000. Influence of alumininum in biological effects of EIF magnetic field stimulation. Electro and Magnetobiol., 19(1): 57-68.

Ruzic, R., N. Gogala. and I. Jerman.1998. Water stress reveals effect of Elf magnetic fields on the growth on seedling. Electro and Magnetobiol., 17(1): 17-30.

Salumee, A.K. 2007. Detection Zeraalenone in yellow corn and shorthand toxicity. M. Sc. thesis, Department of Plant Protection. College of Agriculture. Baghdad University.

Scarselletti, R. and Faull, J. 1994. Invitro activity of 6-pentyl-alpha-pyrone a metabolite of $T$. harzianum in the inhibition of $R$. solani \& Fusarium oxysporum f. sp. lycopersici. Mycol. 
Res., 98(10): 1207-1209.

Starmer, J.E. 1996. Magnetic treatment of swimming pool water for enhanced chemical oxdatin and disinfecting M.sc. thesis. Grand field university. School of Water Scinses.

Sueda, M., A. Katsuki., M. Nonomura., R. Kobayashi., and Y. Tanimoto. 2007. Effects of high magnetic field on water surface phenomena. J. Phys. Chem., (111): 14389- 14393.

Szkatula, A., M. Balanda and K. Kopeck. 2002. Magnetic treatment of industrial water silica activation. Eur. Phys. J., 18: 41-49.

Toajn, A.M.M. 1979. Glasshouse environment, Basra University Press, 571-573.

Toledo, E.J.L., T.C. Ramalho, and Z.M. Magriotis. 2008. Influence of magnetic field on physical-chemical properties of the liquid water: Insights from experimental and theoretical models. J. Mol. Structure, 888: 409415.

Toledo, E.J.L., T.C. Ramalho., and Z.M. Magriotis. 2008. Influence of magnetic field on physical-chemical properties of the liquid water: Insights from experimental and theoretical models. J. Mol. Structure, 888: 409415.

Vasilevski, G. 2003. Perspectives of the application of biophysical methods in sustainable agriculture. Bulg. J. Plant Physiol., Special Issue. 179-186.

Whipps, J.W. 1987. Effect of media on growth and interactions between arrange of soil-borne glasshouse pathogens and antagonistic fungi. New Phytol., 107: 127-142.

\section{How to cite this article:}

Noor K.K. Al-Zubaidi. 2016. Study the Integration of Bio-Resistance and Magnetic Field in the Fight against Disease Rot Seeds and Seedling Death Caused by Two Fungi Fusarium graminiarum and Rhizoctonia solani on the White Corn Sorghum bicolar $L$. Int.J.Curr.Microbiol.App.Sci. 5(12): 507-518. doi: http://dx.doi.org/10.20546/ijcmas.2016.512.055 